\title{
Erratum to: More advanced or aggressive colorectal cancer is associated with a higher incidence of "high-grade intraepithelial neoplasia" on biopsy-based pathological examination
}

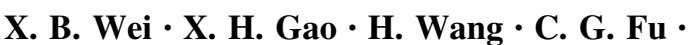 \\ W. Q. Zheng $\cdot$ J. M. Zheng $\cdot$ W. Zhang $\cdot$ L. J. Liu
}

Published online: 15 June 2012

(C) Springer-Verlag 2012

\section{Erratum to: Tech Coloproctol}

DOI 10.1007/s10151-012-0827-4

Owing to an unfortunate misunderstanding, the name of the authors' hospital was rendered wrongly in this article. Its correct name is Changhai Hospital.

Moreover, the original manuscript failed to include a note about the contributions of the first two authors. This omission is rectified here.

Xu Biao Wei and Xian Hua Gao contributed equally to this article.

The online version of the original article can be found under doi:10.1007/s10151-012-0827-4.

X. B. Wei · X. H. Gao - H. Wang - C. G. Fu (凹) - W. Zhang ·

L. J. Liu

Department of Colorectal Surgery of Changhai Hospital,

Second Military Medical University, Shanghai 200433, China

e-mail: fugang416@126.com

W. Q. Zheng · J. M. Zheng

Department of Pathology of Changhai Hospital,

Second Military Medical University, Shanghai 200433, China 